\title{
Urša Geršak, Alejandro Rodríguez Díaz del Real, Maja Šabec (ur.): Španija 1975-2015: štirideset let tranzicije
}

Ljubljana: Znanstvena založba Filozofske fakultete Univerze v Ljubljani, 2017, 181 str.

Znanstvena monografija Španija 1975-2015: štirideset let tranzicije je eno redkih del v slovenskem prostoru, ki si prizadevajo kritično osvetliti obdobje španske tranzicije in ponovno proučiti tiste družbenopolitične vidike, ki so igrali bistveno vlogo pri vzpostavljanju sodobne španske države. Monografijo sestavlja deset prispevkov slovenskih in španskih strokovnjakov, ki z antropološke, sociološke, zgodovinske, literarne in filozofske perspektive problemsko pretresejo špansko tranzicijo ter predstavijo osrednje značilnosti španske politike, družbe in gospodarstva $\mathrm{v}$ zadnjih štiridesetih letih. Vse povezuje enak osrednji cilj: pokazati na nujnost ponovnih branj predvsem tistih zgodovinskih dejstev, ki so bila, še posebej v Španiji, prikrita in zamolčana. S tem se nedvoumno postavlja pod vprašaj tolikokrat izpostavljena vloga $t$. i. "mirne tranzicije«, ki se je v svetu ustoličila kot nekakšna blagovna znamka, celo kot vzor predvsem latinskoameriškim vladam po padcu diktature vojaških hunt, po padcu berlinskega zidu pa tudi vzhodnoevropskim državam.

Monografijo odpira zgovoren prispevek antropologa Gašperja Kralja, ki se osredotoči na polemičnost razprave o španski tranziciji: na eni strani je uradna ali "mitična« zgodba, ki jo omogoča t. i. pakt pozabe (med strokovnjaki se je uveljavil celo termin »memoricid«), na drugi pa je kritična zgodba o tranziciji, ki ji lahko prisluhnemo šele $\mathrm{v}$ zadnjem desetletju. Skozi literarna dela sodobnega španskega pisatelja Javierja Cercasa, pripadnika t. i. generacije vnukov državljanske vojne in znanega kritika "mitične» tranzicije, se v prispevku razkrije nadaljevanje različnih manifestacij frankističnega režima $\mathrm{v}$ sicer demokratični ureditvi, tudi kot posledica »izbrisa republikanskega spomina«.

Zgodovinar David Heredero Zorzo raziskuje še vedno prisotne ostanke frankističnega režima, ki so tako globoko zakoreninjeni v sodobni španski družbi, da se jih mnogokrat ljudje niti ne zavedajo. V prispevku se namreč razkrije pomembno dejstvo, da je še štiri desetletja po Francovi smrti španska družba razdeljena na t. i. "rdeče» (leve) in »črne« (desne), pri čemer gre po avtorjevem mnenju za skrajnejšo delitev kot v drugih zahodnih družbah, tudi zato, ker ostaja nekakšen družbeni tabu, 
o katerem se javno ne govori, vendar pa ideološko močno zaznamuje družbeno življenje. Avtor navedeno podkrepi z različnimi primeri, kot je na primer kontinuiteta frankističnih prijemov na področju sodne oblasti, še vedno obstoječe poimenovanje ulic po predstavnikih frankističnega režima in podobno. Avtor zato izpostavi potrebo po odprti razpravi znotraj javnega diskurza, predvsem v smislu preseganja obstoječih delitev.

Zgodovinar Ricard Conesa Sánchez izpostavi vprašanje spominskih obeležij in problematiko izenačevanja žrtev, konkretno sicer skozi analizo žalovanja in spomina $\mathrm{v}$ Barceloni, ko komentira primer ureditve grobišča na Montjuïcu, Fossar de la Pedrera, hkrati pa se v prispevku pokaže, da gre za univerzalno družbenopolitično temo, ki mora stopiti v ospredje, da bi bilo lahko tudi v javnem diskurzu omogočeno soočenje s preteklostjo.

O namerno zamolčanih dogodkih iz obdobja diktature spregovori hispanistka Urša Geršak, ki v svojem prispevku predstavi občutljivo temo sistematičnega ugrabljanja in nezakonitih posvojitev otrok po španski državljanski vojni. Presenetljivo in pretresljivo je, da so ti odvzemi trajali vse do devetdesetih let 20. stoletja, ko je bila Španija uradno demokratična država že skoraj dve desetletji. Tranzicija bodisi ni uspela bodisi ni želela prekiniti z metodami frankističnega režima in s težnjami po nadzorovanju družbene sestave, zgovorno pa je tudi, da primeri odvzetih otrok še danes niso bili ustrezno pravno obravnavani.

Sociolog Damjan Mandelc usmeri pogled na zgodovinsko in družbenopolitično dogajanje v Španiji med frankizmom in tranzicijo, predvsem skozi pojav novih političnih gibanj in strank (Podemos, Ciudadanos), katerih ideje so močno odmevale tudi $\mathrm{v}$ evropskem prostoru. Hkrati $\mathrm{v}$ prispevku predstavi osrednje značilnosti katalonskega in baskovskega independentizma, študijo pa zaokroži umestitev aktualnega političnega in socioekonomskega stanja Španije v evropski in globalni kontekst.

Prispevek sociologa Gorazda Kovačiča se osredotoči na vzroke za nastanek nepremičninskega balona ter uničujoče posledice gospodarske in finančne krize leta 2008. Avtor zavzame kritični odnos do Evrope in njenih institucij, ki v takih primerih članicam naložijo, naj same nosijo glavnino stroškov. Tudi v tem prispevku se izpostavi pomen organiziranega delovanja civilne družbe ter nastanka že omenjenih gibanj in strank v luči zahteve po korenitih družbenih in političnih spremembah.

Če je govora o španski tranziciji, seveda ne moremo mimo baskovske oborožene organizacije ETA, o kateri pa se zdi, da v španski družbi še danes kljub premirju ni mogoča odprta, predvsem pa pluralna razprava. Zgodovinar Benjamín Olmedo 
Cañas namreč predstavi organizacijo od njenega nastanka do današnjih dni skozi državno politiko protiterorističnih ukrepov, vendar pa nam pogled vodijo oči uradne zgodovine, saj v prispevku, na primer, niso problematizirani vzroki njenega nastanka, delovanja in družbenopolitične vloge.

Sledita zanimiva in zgovorna literarna prispevka: hispanistka Branka Kalenić Ramšak analizira posledice dolgotrajne in uničujoče literarne cenzure na razvoj španskega romana $\mathrm{v}$ času frankizma in po njem ter pokaže, da do večjih premikov $\mathrm{v}$ smeri pluralizma tematik in pripovednih tehnik $\mathrm{v}$ španski literaturi pride šele proti koncu 20. stoletja. Spodbudna je avtoričina ugotovitev, da literarna beseda vselej najde pot ter da se španska literarna misel v obdobju tranzicije vendarle uspe izogniti enosmernim političnim pogledom, kar podkrepi s predstavitvijo dveh vélikih sodobnih pisateljev, Enriqueja Vila-Matasa in Roberta Bolaña, ki je sicer Čilenec, vendar je večji del svojega opusa napisal v Španiji. Drugi literarni prispevek nas popelje v svet baskovske književnosti, ki je šele v času tranzicije lahko zaživela, saj je bila, tako kot baskovski jezik, v času frankizma preganjana in prepovedana. Hispanistka Barbara Pregelj predstavi razvoj, specifično vlogo in, ne nazadnje, emancipacijo baskovske književnosti, ki so ji bile vse do zadnje tretjine 20. stoletja družbeno-zgodovinske okoliščine nenaklonjene, danes pa $\mathrm{v}$ baskovskem jeziku nastaja ena zanimivejših evropskih literatur.

Pahljačo pogledov na špansko tranzicijo sklene prispevek hispanista Alejandra Rodrígueza Díaza del Reala, ki predstavi razvoj španske filozofije v zadnjih štirih desetletjih, predvsem prehod od začetnega močno politiziranega pojmovanja vloge filozofije do njene ločitve od univerze, pa spet do ponovne vzpostavitve filozofske misli kot kritičnega dejavnika v zadnjih letih. V prispevku spoznamo nekaj vidnejših sodobnih španskih filozofskih mislecev, med katerimi dobršen del diskusije vodijo filozofinje.

Interdisciplinarno zasnovana monografija Španija 1975-2015: štirideset let tranzicije jasno in argumentirano združuje različne poglede na pomembno obdobje španske polpretekle zgodovine, ki je v zadnjih letih predmet vse pogostejših, vendar še vedno ne dovolj odprtih javnih razprav. Vsi prispevki so napisani v jasnem, terminološko ustreznem strokovnem jeziku, razprave so prepričljive in podprte s številnimi strokovnimi referencami, večino spremlja tudi slikovno gradivo. Monografija bo nedvomno zanimiva tako za hispaniste, zgodovinarje, literarne komparativiste in sociologe kot tudi za širšo javnost, saj o tem obdobju španske zgodovine v slovenskem prostoru ni mogoče zaslediti veliko kritičnih oziroma problemsko zasnovanih študij.

Posebej dragoceno je, da so avtorji tako slovenski kot španski strokovnjaki z različnih področij (zgodovina, filozofija, španski jezik in književnost, antropologija), 
ki z vnovičnimi premišljevanji in prevpraševanji o španski tranziciji bralcu omogočajo objektivnejši vpogled ter ga spodbujajo h kritičnemu razmišljanju ne samo o specifikah španske družbene stvarnosti, temveč tudi o širših družbeno-gospodarskih pojavih ter o problematiki vrednotenja zgodovinskega spomina nasploh. In, če si sposodimo besede španskega pisatelja Javierja Cercasa o nalogi spreminjanja sveta, ki naj bi jo imela angažirana literatura, lahko z gotovostjo trdimo, da bo pričujoča monografija, če že ne spremenila svet, pa prav gotovo pripomogla k spremembi percepcije nekaterih pomembnih zgodovinskih dogodkov. $S$ tem predstavlja nepogrešljiv delček v mozaiku kritičnega razmišljanja o zgodovinskih in družbenopolitičnih dogajanjih $\mathrm{v}$ sodobnem evropskem prostoru. 